\title{
O RELATÓRIO FINAL DA CNV E A NOMEAÇÃO DOS PERPETRADORES DE GRAVES VIOLAÇÕES AOS DIREITOS HUMANOS
}

\section{THE CNV FINAL REPORT AND THE NAMING OF PERPETRATORS OF SERIOUS HUMAN RIGHTS VIOLATIONS}

\begin{abstract}
${ }^{1}$ Amanda Cataldo de Souza Tilio dos Santos
\section{RESUMO}

Em dezembro de 2014, a Comissão Nacional da Verdade divulgou seu Relatório Final. Esse documento tornou público um rol de autores de graves violações de Direitos Humanos, elencados segundo níveis de responsabilidade do Direito Administrativo. O presente artigo tem como objetivo analisar a nomeação dos perpetradores no contexto jurídico-político brasileiro. Por fim, com base em uma teoria do Direito Internacional será considerado como os níveis de responsabilidade indicados pela CNV apontam o caminho para uma futura responsabilização jurisdicional dos agentes estatais, seja diante das Cortes domésticas ou mesmo internacionais.
\end{abstract}

Palavras-chave: Relatório final, Comissão nacional da verdade, Direitos humanos, Direito à verdade, Autoria, Responsabilidade crimina

\begin{abstract}
In December 2014, the National Truth Commission released its Final Report. This document revealed a list of perpetrators of serious human rights violations, grouped according to levels of responsibility borrowed from the administrative law. This essay aims to analyze the naming names mechanism in face of the Brazilian juridical-political context. Finally, based on a theory of international law, will be demonstrated how these levels of responsibility point a way for a future judicial accountability before domestic or even international Courts.
\end{abstract}

Keywords: Final report, National truth commisssion, Human rights, Right to truth, Authorship, Criminal liability

\footnotetext{
${ }^{1}$ Mestranda em Direito pela Pontifícia Universidade Católica do Rio de Janeiro - PUC, Rio de Janeiro (Brasil). E-mail: mandyy2005@hotmail.com
} 


\section{Introducão}

Há pouco mais de um ano, um importante passo foi dado no âmbito do processo transicional brasileiro. Em dezembro de 2014, a Comissão Nacional da Verdade publicou seu Relatório Final, reescrevendo um capítulo doloroso da história do país que inclui o período da Ditadura Civil-Militar instaurada em 1964. Através de uma lente multidisciplinar, proporcionada por pesquisadores de diversas áreas de conhecimento, o Relatório contestou veementemente a "narrativa dos vencedores", evidenciando, através de documentos oficiais, diligências e testemunhos, as graves violações de Direitos Humanos empreendidas com fulcro em uma Política de Estado.

Além de propiciar a verdade dos fatos e as circunstâncias, com fundamento em sua lei de instituição, a CNV tornou público um rol de autores de graves violações de Direitos Humanos, elencados com base em níveis de participação emprestados do Direito Administrativo. Diante disso, apesar do caráter extrajudicial da Comissão, que a impossibilita de responsabilizar formalmente os perpetradores de graves violações, a indicação destes nomes possui efeitos sociais significativos para as vítimas, seus algozes e toda a comunidade. Se, por um lado, abriria caminho para a assunção de culpa do perpetrador e a concessão de perdão individualizado do vitimado; por outro, em um primeiro momento, poderia desencadear uma punição social aos agentes, com efeitos semelhantes aos "escrachos" argentinos.

Contudo, o desvelamento da verdade sobre os fatos, circunstâncias e autoria propiciado pelos trabalhos de uma comissão da verdade não deve ser considerado como o encerramento do processo transitório de um país. Ao contrário, esta verdade evidenciada tem a potencialidade de fundamentar e desencadear um movimento de luta contra a impunidade. Isto porque, para que a sociedade possa reestabelecer a confiança no Estado Democrático devem ser rompidos todos os vínculos com a impunidade e desmanteladas as tramas sociais do crime. Portanto, a verdade emanada por uma comissão da verdade deve ser tida como complementar e uma propulsora de um futuro tratamento jurisdicional. Neste tocante, o próprio Relatório da CNV posiciona-se no sentido da inseparabilidade do binômio Verdade- Justiça no contexto transitório brasileiro, recomendando que se apure juridicamente a responsabilidade dos agentes públicos perpetradores de graves violações. 
O presente trabalho objetiva demonstrar como os níveis de participação apontados pelo Relatório Final da CNV pavimentam um caminho para uma futura responsabilização dos agentes perpetradores de graves violações. Baseando-se em diferentes níveis de responsabilidade derivados do Direito Administrativo, a CNV sugere que as graves violações não foram cometidas como atos isolados de alguns agentes insubordinados, mas resultaram de diretrizes do próprio regime repressivo. A partir desta concepção de responsabilidade, o propõe-se uma alusão à Teoria do Domínio por Organização. Desenvolvida pelo penalista alemão Claus Roxin, essa teoria promove um alargamento da noção de autoria mediata abrindo a possibilidade de responsabilização criminal dos "autores de escritório". Nesse sentido, coaduna com o entendimento da $\mathrm{CNV}$ quanto à existência de responsabilidade daqueles que possuíam poder de mando e conduziam o aparato repressivo do regime, uma cadeia que se constituía desde a alta cúpula do Regime até o agente perpetrador direto. É importante salientar que esta teoria já encontra precedentes jurisprudenciais no Cone Sul, como por exemplo, a condenação do ex-presidente Alberto Fujimori pela Corte Suprema do Peru.

\section{1- Breves notas sobre a consolidacão internacional do direito à verdade}

$\mathrm{O}$ direito à verdade, positivado na lei de instituição da $\mathrm{CNV}^{1}$, possui uma longa trajetória no Direito Internacional. Desde o Protocolo Adicional I às Convenções de Genebra, de 1977, que reconhecia explicitamente o direito das famílias a saber sobre o ocorrido aos seus entes em um ambiente de conflito; até a Convenção Internacional para a Proteção de Todas as Pessoas contra os Desaparecimentos Forçados, de 2010, que possui uma redação semelhante (Relatório Final da CNV, Vl. I, Cap. 1, 2014).

No desenvolvimento do conceito no Sistema Internacional, deve-se ressaltar o Conjunto de princípios para a proteção e promoção dos direitos humanos por meio do combate à impunidade (os "Princípios Joinet"), relatório emitido pela Comissão de Direitos Humanos da ONU em 1997. Nesse relatório é reconhecido o "direito a saber" como sendo um direito individual da vítima e de seus familiares, ao passo que também seria um direito coletivo relacionado ao dever estatal de recordar e prevenir qualquer prática de revisionismo

\footnotetext{
${ }^{1}$ Art. $1^{\circ}$ da Lei 12.528/11: "É criada, no âmbito da Casa Civil da Presidência da República, a Comissão Nacional da Verdade, com a finalidade de examinar e esclarecer as graves violações de direitos humanos praticadas no período fixado no art. $8^{\circ}$ do Ato das Disposições Constitucionais Transitórias, a fim de efetivar o direito à memória e à verdade histórica e promover a reconciliação nacional" (grifo nosso).
} 
ou negacionismo. O relatório da ONU enfatiza que a história de opressão é pertencente ao patrimônio de um povo e, por conseguinte, deve ser preservada ${ }^{2}$.

Já em 2005, a ONU lançou o Conjunto atualizado de princípios, no qual esclarece que a impunidade ocorreria diante da incapacidade dos Estados em observar o dever de assegurar o direito inalienável das vítimas e da sociedade em saber a verdade sobre as violações; assim como adotar medidas apropriadas quanto aos perpetradores, tais como a instauração de processo, julgamento e punição; a obrigação de prover às vítimas os remédios efetivos; de garantir a reparação de seus danos; e, por fim, a obrigação de tomar medidas destinadas à prevenção de repetição do ocorrido no passado (Relatório da CNV, Vl. I, Cap. 1, 2014).

Em âmbito regional, o direito à verdade começou a ganhar contornos nas decisões da Corte IDH, sobretudo no caso Caso Bácama Velásquez vs. Guatemala (2002). A Corte reconheceu que a dimensão individual do direito à verdade se referia ao direito de as famílias saberem o que ocorreu aos seus entes queridos, proporcionando-lhes assim uma forma de reparação. Já a dimensão coletiva do direito à verdade implicaria no direito da sociedade de "ter acesso à informação essencial para o desenvolvimento dos sistemas democráticos"3. Deste modo, pode-se conceber que haveria, portanto, um interesse da sociedade no conhecimento dos fatos e, consequentemente, na responsabilização dos agentes que empreenderam graves violações dos direitos humanos.

Por conseguinte, no julgamento do Caso Gomes Lund vs Brasil, em 2010, a Corte reiterou o entendimento já presente em julgados anteriores sobre o direito à verdade e a luta contra a impunidade. Nesta mesma decisão, a Corte ressaltou a tendência dos países da região em rever suas leis de anistia e reconheceu a incompatibilidade destas com as obrigações assumidas internacionalmente pelos Estados. Diante de tais considerações, a Corte instou o Brasil a promover a investigação dos fatos e a responsabilizar os perpetradores das graves violações dos Direitos Humanos.

\footnotetext{
${ }^{2}$ Sentença na íntegra disponível: ORGANIZAÇÃO DAS NAÇÕES UNIDAS. La cuestión de la impunidad de los autores de violaciones de los derechos humanos (civiles y políticos). Informe final elaborado e revisado por M. Louis Joinet. E/CN. 4/Sub. 2/1997/20/Rev. 12 de outubro de 1997.

${ }^{3}$ Em linhas gerais, o caso versa sobre a tortura e o desaparecimento do Comandante da "Unidad Revolucionaria Nacional Guatemalteca", durante a guerra civil. CORTE INTERAMERICANA DE DIREITOS HUMANOS. Caso Bácama Velásquez vs. Guatemala, 22 fev. 2002.
} 
Perante o Sistema Internacional de Proteção aos Direitos Humanos e a jurisprudência da Corte IDH, infere-se o direito inalienável das vítimas e da sociedade em saber a verdade sobre as violações, incluindo a dimensão da autoria dos fatos. Caso a lei de instituição da CNV não versasse sobre o conhecimento da autoria das graves violações de Direitos Humanos, incorreria em um afastamento da normativa internacionalmente consolidada, reforçando a lógica do esquecimento em detrimento da verdade histórica.

Ao mesmo tempo, no âmbito da luta contra a impunidade, tem-se o entendimento de que a responsabilidade dos Estados não se esgota na efetivação do direito à verdade, havendo uma obrigação estatal quanto à responsabilização dos agentes perpetradores. Em consonância com os sistemas global e regional, conforme será visto adiante, a CNV posicionou-se quanto a inseparabilidade do binômio Verdade-Justiça no contexto transitório brasileiro.

\section{2- O Relatório Final da CNV: A importância do naming names no contexto da luta contra impunidade}

De acordo com o mandato legal da Comissão Nacional da Verdade, definido na Lei $\mathrm{n}^{\mathrm{o}}$ 12.528/2011, um dos objetivos da CNV era o de "promover o esclarecimento circunstanciado dos casos de tortura, mortes, desaparecimentos forçados, ocultação de cadáveres e sua autoria, ainda que ocorridos no exterior (...)" (Art $3^{\circ}$, II - grifo nosso). Nesse sentido, em cumprimento ao disposto na Lei foi elaborado o Capítulo 16, constante no Volume I do Relatório da CNV, subscrito por todos os seus membros. Intitulado "A Autoria das Graves Violações de Direitos Humanos", o capítulo trouxe um rol não exaustivo de autorias de graves violações de direitos humanos que puderam ser conhecidas e comprovadas através dos meios adotados pela Comissão.

Faz-se necessário ressaltar que a indicação dos nomes dos perpetradores das graves violações de direitos humanos foi uma prática adotada em diversas comissões da verdade que precederam a CNV, tais como a do Chade e a de El Salvador. Não se trata de uma inovação brasileira, contudo, a peculiaridade da lei de instituição da CNV reside na adoção do termo "autoria", ao invés de "nomeação" (em inglês, naming names), uma palavra que carrega um "peso maior", que poderia remeter um leitor leigo à esfera jurídica de responsabilização dos referidos autores. 
Na realidade, a CNV elaborou um rol de nomes de agentes públicos ${ }^{4}$, elencados com base nas evidências angariadas pela Comissão, que não seguem os parâmetros processuais de produção de provas e nem observam estritamente os princípios do contraditório e da ampla defesa, aplicáveis aos processos administrativo e judicial. A CNV não possui caráter persecutório, ao passo que a nomeação de autoria das graves violações de Direitos Humanos por si só não constitui responsabilização em quaisquer esferas. Desse modo, como não há uma responsabilização formal em quaisquer planos, mas tão somente a indicação da autoria dos fatos (em consonância com a concepção internacionalmente aceita de direito à verdade), o princípio da presunção de inocência também não seria aplicável no âmbito da CNV.

O rol divulgado pela CNV não é exaustivo, considerando-se que foram listados os 377 nomes de agentes que puderam ser identificados por meio de documentos e testemunhos, de acordo com os parâmetros mínimos de prova balizados pela Comissão. Ademais, as condutas (comissivas e omissivas) ensejadoras de nomeação dos agentes relacionam-se exclusivamente às graves violações de Direitos Humanos priorizadas na pesquisa conduzida pela CNV, quais sejam: tortura, morte, desaparecimento forçado e ocultação de cadáver (Relatório Final da CNV, V1. I, Cap. 16, 2014).

Diante da natureza não persecutória, a publicialização da autoria das graves violações de Direitos Humanos por parte da CNV possui implicações sociais importantes. Se por um lado a divulgação de uma cadeia de perpetradores relacionados a cada caso específico de grave violação poderia ensejar a assunção de culpa do perpetrador e a concessão de perdão das vítimas; por outro, pode-se apontar para a possibilidade de uma punição social aos algozes, nos moldes dos "escrachos" $\operatorname{argentinos}^{5}$. Ademais, em um primeiro momento, a publicialização de seus nomes os levaria a um ostracismo social e repulsa por parte de empregadores, vizinhos, familiares, etc.

Ao mesmo tempo, a delimitação dos nomes dos envolvidos teria o condão de retirar uma "mácula" ainda presente das instituições militares, que acaba por suscitar uma

\footnotetext{
${ }^{4}$ Deve-se considerar que nem todos os implicados eram servidores ou funcionários públicos. Por exemplo, Hilário José Corralis era marceneiro e pequeno empresário, ligado a oficiais do Exército e da Polícia Militar (Relatório da CNV, 2014, Vl. I, Cap. 16, p. 896). A denominação agentes públicos é utilizada de modo amplo, abarcando os agentes em colaboração com o Estado.

${ }^{5} \mathrm{O}$ "escracho", como conhecido na Argentina e no Uruguai, é um tipo de mobilização em que se evidencia de maneira pública um fato condenável relacionada a uma pessoa ou lugar.
} 
desconfiança generalizada em relação aos membros das Forças Armadas. Nesse sentido, a nomeação dos agentes públicos envolvidos diretamente na prática das graves violações tem o viés de eduzir o estigma social em relação aos meios militares. Não se deve olvidar que, apesar de as graves violações de Direitos Humanos serem amparadas por uma Política de Estado, havia setores militares e burocráticos dissidentes que sofreram fortes represálias por parte dos setores repressivos (Relatório Final da CNV, Vl. II, Cap. 1, 2014).

Por outro lado, o mecanismo de naming names constitui uma parte importante do processo de truth-telling principalmente quando os sistemas judiciais funcionam de forma ineficiente (HAYNER, 2001). No caso brasileiro, a interpretação do STF em relação à Lei de Anistia de 1979 impõe um óbice à prestação jurisdicional às vítimas ${ }^{6}$. Desse modo, a indicação de um rol de autores de graves violações de Direitos Humanos, a partir de provas documentais e testemunhais colhidas e reunidas pela CNV, poderia munir a sociedade civil, nacional e internacional, de informações importantes para fundamentar petições perante órgãos jurisdicionais e, consequentemente, a promover a responsabilização individual dos envolvidos.

Um exemplo de como um relatório emitido por uma comissão da verdade tem potencialidade para contribuir como evidência às Cortes pode ser verificado no Caso Pinochet, de 1998. Nesse episódio, o juiz espanhol Baltasar Garzón emitiu uma ordem de prisão em desfavor do ex-ditador chileno pela morte e tortura de cidadãos espanhóis, com base no Princípio da Jurisdição Universal. Em sua fundamentação, o juiz considerou as informações contidas no relatório da Comissão da Verdade, Justiça e Reconciliação do Chile, o chamado Relatório Rettig de 1991, inclusive citando-o diretamente na ordem de prisão (HAYNER, 2001, p. 38).

\footnotetext{
${ }^{6}$ Em 2010, o Supremo Tribunal Federal (STF) decidiu pela constitucionalidade da Lei de Anistia ao julgar a Arguição de Descumprimento de Preceito Fundamental (ADPF) n ${ }^{\circ} 153$. O Supremo inferiu que a Lei de Anistia estava relacionava a fatores históricos que ocorreram no âmbito de uma transição negociada politicamente e, portanto, esta lei, promulgada durante a Ditadura Civil-Militar, teria sido recepcionada pela Constituição "cidadã" de 1988.
} 


\section{3- Uma possível conjugacão entre a "justica das vítimas" e a luta contra impunidade}

Conforme salienta o Professor Juan Méndez, há duas vantagens das Comissões da Verdade diante das Cortes jurisdicionais: a primeira seria a concentração de todo esforço em um período de tempo limitado e a capacidade de reunir informações de variadas fontes; a segunda seria que no curso desse processo as vítimas e suas famílias seriam "ouvidas" e respeitadas em sua dignidade, como nunca foram antes (MÉNDEZ,1997).

No âmbito de uma transição "negociada" e "por cima", como o processo brasileiro, os crimes cometidos por agentes estatais foram ocultados por versões oficiais, que perduraram por anos após a transição à democracia. Parte significativa da mídia da época divulgou à população versões não apuradas de supostos suicídios, enfrentamentos, acidentes, etc. Somouse a esta situação uma política de esquecimento com vistas à reconciliação nacional, na qual se insere a Lei de Anistia de 1979. Aos indivíduos lhes era exigido que abdicassem do direito à verdade em prol da estabilidade política e social da nação.

Diante de tal contexto transitório, a vítima não encontrou um espaço de fala no qual sua narrativa pudesse ser ouvida e, consequentemente, acabou silenciada. Ao mesmo tempo, prevaleceu a narrativa estatal baseada amplamente na legalidade do Regime instaurado, com fulcro em seus Atos Institucionais e na Lei de Segurança Nacional. Negou-se o status de vítima à vários cidadãos diante do não reconhecimento das graves violações de direitos humanos empreendidas por agentes estatais. Deste modo, a vítima foi negligenciada e teve sua alteridade completamente negada.

Sob o pretexto de uma desejada "reconciliação nacional" e da anistia política "ampla e irrestrita”, a via jurisdicional se fechou àqueles vitimados pelo regime, que buscavam tanto a reparação quanto a verdade sobre os fatos. Diante do óbice jurisdicional, a Comissão Especial sobre Mortos e Desaparecidos Políticos (criada pela Lei 9.140/1995) e a Comissão de Anistia (criada pela Medida Provisória 2.151/01) se tornaram os mecanismos acessíveis às vítimas, primando essencialmente por uma reparação moral e econômica. Por anos, tal processo reparatório constituiu o eixo estruturante da política de transição no Brasil (TORELLY, 2012). 
Contudo, no ano de 2007, uma iniciativa da Comissão de Anistia abriu um novo capítulo no processo de transição brasileiro. As chamadas Caravanas de Anistia percorreram o país em busca de testemunhos das vítimas, além de apreciarem in loco processos referentes a ex-perseguidos políticos e de realizar atos públicos com o fito de resgatar a memória dos anos de repressão no Brasil. Como resultado, a narrativa das vítimas e sua participação no processo transicional foi valorizada após um longo período de silenciamento e negligenciamento (JUNIOR, CARLET, et al.; 2010).

A Comissão Nacional da Verdade nasceu após essas primeiras iniciativas e, indubitavelmente, pôde contar com tal legado para cumprir com seu mandato legal. Além de reunir importante material já constituído no âmbito das supracitadas comissões, de diversas outras comissões (tais como as municipais, estaduais, universitárias) e de organizações da sociedade civil, a equipe de pesquisadores da CNV realizou novas oitivas de testemunhas, depoimentos, diligências, perícias, audiências públicas e pesquisas documentais durante os seus dois anos de funcionamento.

Diante das dificuldades em relação à disponibilização do acervo documental das Forças Armadas ${ }^{7}$ e as negativas e o silêncio dos convocados como depoentes ${ }^{8}$, o testemunho das vítimas tornou-se uma fonte primordial para que se efetivasse o direito à verdade. Deve-se considerar, ademais, que um dos meios mais eficazes de se desvelar os acontecimentos e as violações passadas é o testemunho das vítimas, já que somente estas são capazes de reproduzir todas as dimensões do horror que lhes foi imputado. Considerando a força do testemunho para a reconstrução dos acontecimentos, a CNV recorreu à memória das vítimas, “dando voz ao sofrimento da injustiça sofrida, as sequelas presentes de um passado que não passou" (RUIZ, 2012. p. 72).

A centralidade do testemunho da vítima nos permite uma análise dos fatos históricos tomando como ponto referencial o seu sofrimento. Nesse sentido, pode-se dizer que a importância de se ouvir as vítimas vai além da construção de um lastro probatório para que se

\footnotetext{
${ }^{7}$ Conforme o aviso $n^{\circ}$ 195/2010, que foi encaminhado à Casa Civil, o Exército, a Marinha e a Aeronáutica afirmaram que não teriam mais documentos do período de 1946 à 1988 em seus acervos, visto que estes teriam sido destruídos com base na legislação vigente à época.
} 
indique as autorias e as circunstâncias das graves violações de Direitos Humanos; mas, fundamentalmente, a invocação da memória das vítimas representa um ato de responsabilidade histórica diante daqueles que sofreram injustiças no passado, devolvendolhes a sua alteridade ora negada (RUIZ, 2012). Neste sentido, tem-se a dimensão de justiça anamnética, cuja figura central é a vítima e sua memória viva da violência, fundamental para a desconstrução da narrativa oficial que encobre a barbárie dos tempos passados.

Sob esta perspectiva, há de se considerar como o óbice legal à apuração dos fatos, das circunstâncias e da participação dos autores de graves violações aos direitos humanos enseja uma nova injustiça às vítimas, visto que lhes nega o direito à verdade, além de renegar suas memórias e seu sofrimento ainda presente e latente. Por conseguinte, a Lei de Anistia representaria um ato oficial de esquecimento, considerando-se que promoveria uma "negação hermenêutica das vítimas, sua segunda morte” (RUIZ, 2012, p.77)

O filósofo espanhol Reyes Mate (2008a) nos recorda que há determinados efeitos danosos que constituem injustiças, que vão além da lei positiva e encontram abrigo nos princípios morais. Diante desta consideração, Mate analisa os diferentes danos causados pela violência às vítimas e à sociedade. Inicialmente, verifica um dano pessoal, que pode ser tanto a morte, a tortura, a mutilação, o medo. Há um segundo dano, o político, que é a negação da cidadania, isto porque o perpetrador entende que a vítima é irrelevante para a comunidade política a qual ele aspira. Por fim, há um dano social, no qual a sociedade é a vítima, pois essa se torna empobrecida e fraturada. Torna-se empobrecida porque há uma privação tanto da vítima quanto de seu algoz. O perpetrador se torna um delinquente, coloca-se fora da sociedade e também da humanidade. Nesse sentido, a sociedade é também fraturada (MATE, 2008a).

Portanto, diante destes três tipos de danos, algumas medidas no âmbito da justiça de transição são prioritárias. O dano pessoal é fundamentalmente irreparável, mas gera a obrigação de reparação na medida do possível (MATE, 2008a). Nesse sentido, requer respostas públicas de reparações simbólicas, materiais, terapêuticas, dentre outras (GOMEZ, 2014). Já o dano político enseja o reconhecimento daqueles que foram suprimidos ou privados violentamente de seu status de cidadãos (MATE, 2008a). Portanto, requer o reconhecimento 
da sociedade de que as vítimas são verdadeiramente cidadãs, além de medidas relacionadas a fazer conhecer, reconhecer, julgar os responsáveis e resgatar a memória dos crimes cometidos que minaram os laços políticos de convivência (GOMEZ, 2014). Por fim, em relação ao dano social, deve-se recuperar tanto a vítima como o seu algoz. A vítima é recuperada através do reconhecimento de sua cidadania, o que também enseja a reparação do dano político. Os perpetradores, por sua vez, são recuperados por um processo que possui duas etapas: o reconhecimento da culpa pelo dano e o pedido de perdão dos ofensores e, após, a concessão de perdão como uma faculdade exclusiva das vítimas. Deste modo, é inaugurado um novo começo sócio-político (GOMEZ, 2014).

Faz-se mister ressaltar que a participação das vítimas no processo transicional não pode suplantar a atuação dos tribunais, isto é, sua vontade não pode substituir aos procedimentos judiciais, pois tal conduziria à arbitrariedade da vingança. Na realidade, as vítimas possuem uma dimensão de justiça, que difere da justiça procedimental, na medida em que somente elas podem oferecer o perdão ao perpetrador. Com base nos preceitos de "justiça das vítimas" de Reyes Mate, o perdão seria um ato político que teria o condão de restaurar a convivência social, integrando a vítima de forma plena, como pessoa e cidadã. O perdão seria um direito pessoal da vítima que requer uma atitude de arrependimento do agressor pelos atos cometidos, passando a renunciar de seus métodos violentos e de qualquer outra forma de cultura de violência. Assim, o perdão não se daria de uma forma ampla ou massiva, mas seria algo muito pessoal e limitado a casos especiais. As comissões da verdade, neste contexto, propiciariam pontes para que pudesse ocorrer a justiça através do perdão (RUIZ, 2008).

Sob a perspectiva de uma "justiça das vítimas”, que prima pela restauração dos laços sociais de convivência, o conhecimento da identidade dos perpetradores de graves violações de Direitos Humanos faz-se proeminente. Afinal, como seria possível o perdão das vítimas se estas não soubessem a quem perdoar e ao que perdoar? (HAYNER,2001) O perdão, portanto, é incompatível com o esquecimento. Somente a vítima tem o poder de perdoar (MATE, 1999) e, para isso, ela precisa conhecer a verdade sobre os fatos e as circunstâncias, além dos responsáveis pelos danos causados. Portanto, perdão e verdade podem e, devem, coexistir no processo transicional. 
Neste sentido, ao reconhecer expressamente quem são as vítimas e quais agentes estatais individualmente contribuíram para cada caso de grave violação de Direitos Humanos, o Relatório da CNV oportunizaria a assunção de culpa do perpetrador e o pedido pessoal de perdão à vítima e aos seus familiares pela conduta empreendida. Em uma perspectiva de justiça às vítimas, a reintegração do vitimado à sociedade dependeria de seu reconhecimento social, como cidadão, e do reconhecimento por parte do perpetrador do dano cometido (MATE, 2008a).

Para a coletividade, por sua vez, o conhecimento sobre a verdade dos fatos e a consequente indicação dos nomes dos envolvidos poderia inibir uma possível reprodução histórica de violências, funcionando como uma espécie de freio a sujeitos inclinados a uma reprodutividade no presente. Isto porque as atrocidades e barbáries negadas através de atos de esquecimento podem retornar facilmente ao presente que as nega (RUIZ, 2012).

Há autores como Zamora (2013) que sustentam que para que a sociedade como um todo recupere a confiança no Estado Democrático devem ser rompidos por completo os vínculos com a impunidade. Para ele, não basta o perdão das vítimas para a efetividade da reconciliação social, mas para que se possa romper com as tramas sociais do crime é necessário o seu tratamento judicial. Contudo, isto não significa que se deva reduzir a potencialidade da justiça de transição ao tratamento criminal dos algozes: faz-se necessário conjugar a concepção de "justiça da vítima", levando-se em conta seu caráter simbólico e terapêutico, e o interesse coletivo da sociedade no rompimento das tramas sociais do crime.

Empiricamente, a importância de uma complementariedade entre os trabalhos de comissões da verdade e o papel das cortes jurisdicionais já foi comprovada por uma pesquisa realizada por Kim e Sikkink (2010). De acordo com as autoras, a justiça de transição possui um impacto direto sobre as instituições, as práticas e a cultura política das ainda frágeis democracias emergentes. Dentre 100 casos de transição analisados, constatou-se que nos países que criaram comissões da verdade e também optaram por procedimentos judiciais, a era democrática alcançou melhores resultados relativos ao respeito aos direitos humanos, verificando-se nesses inclusive um menor grau de violência policial. 
Partindo de um entendimento que coaduna com a noção de complementariedade dos papéis desempenhados pelas comissões da verdade e pelos tribunais, o Relatório da CNV recomenda a responsabilização formal dos agentes estatais:

"Determinação, pelos órgãos competentes, da responsabilidade jurídica - criminal, civil e administrativa - dos agentes públicos que deram causa às graves violações de direitos humanos ocorridas no período investigado pela $\mathrm{CNV}$, afastando-se, em relação a esses agentes, a aplicação dos dispositivos concessivos de anistia inscritos nos artigos da Lei no 6.683, de 28 de agosto de 1979, e em outras disposições constitucionais e legais" (Vl. I, Cap. 18, p. 965).

A CNV, portanto, posicionou-se pela inseparabilidade do binômio Verdade-Justiça, já consagrado internacionalmente, conforme visto em momento anterior, nos reportes da Comissão de Direitos Humanos da ONU e na jurisprudência da Corte IDH. Ao Estado Democrático cabe prestar contas à sociedade pelas graves violações de Direitos Humanos empreendidas no passado. Não é possível passar uma borracha, silenciar o passado e seguir em frente. A normativa internacional, brevemente apontada, é clara ao dispor que a responsabilidade estatal diz respeito à efetivação do direito à verdade, à reparação dos danos às vítimas e à responsabilização jurisdicional dos perpetradores de graves violações.

\section{4- Uma leitura dos planos de participacão da CNV à luz do Direito Penal Internacional}

Em consonância com a recomendação quanto ao tratamento jurisdicional das graves violações empreendidas, o Relatório nos fornece um panorama de autoria e responsabilidade que encontra abrigo no Direito Penal Internacional. Nesta seção do artigo será proposta uma interpretação dos planos de participação indicados pela CNV à luz de uma teoria de responsabilidade penal internacional, a Teoria do Domínio por Organização. Esse exercício de alusão ao Direito Internacional abre caminho para a superação do entendimento jurisprudencial doméstico de que os crimes cometidos pelos agentes estatais são crimes conexos aos políticos e passíveis de anistia.

De acordo com o Relatório da CNV (Vl. I, Cap. 16, 2014), as graves violações perpetradas durante o Regime Civil-Militar constituíram-se como expressão de decisões 
políticas emanadas das instâncias dirigentes do país, que se refletiam nas estruturas administrativas organizadas de acordo com os princípios da hierarquia e da disciplina, na forma de rotinas de trabalho e padrões de conduta. Diante dessa acepção, é vislumbrada a ascendência hierárquica sobre as atividades de cunho funcionais e administrativas empreendidas pelos agentes públicos indicados como autores diretos das graves violações de direitos humanos.

Ao mesmo tempo, a CNV pontua que as graves violações de Direitos Humanos cometidas durante o Regime Civil-Militar caracterizam-se como crimes contra a humanidade no âmbito do jus cogens internacional, o que os torna imprescritíveis e impassíveis de anistia ou indulto. Assim, dispõe que essas graves violações, quando praticadas em um quadro de um ataque generalizado ou sistemático contra a população civil, passam a adquirir a caracterização de crime contra a humanidade, conforme disposto no Artigo 7º alínea "g", do Estatuto de Roma do Tribunal Penal Internacional (CNV, Vl. I, Cap. 7, 2014).

Levando-se em conta seu caráter de comissão extrajudicial (com mandato e prazo instituídos por lei) e a natureza dos nomeados como agentes do Estado, a CNV optou por reconhecer distintos planos de participação dos agentes, utilizando-se como base teórica o Direito Administrativo. Por conseguinte, houve uma divisão em: responsabilidade políticoinstitucional, responsabilidade pelo controle e gestão de estruturas e procedimentos e, finalmente, responsabilidade pela autoria direta.

Inicialmente, no âmbito da responsabilidade político-institucional são incluídos membros da alta cúpula do Regime. De acordo com o Relatório, “(...)agentes do Estado à função de conceber, planejar ou decidir políticas de persecução e repressão de opositores ao regime militar” (Vl. I, Cap. 16, p.844). São listados os Presidentes da República, responsáveis pela adoção da Doutrina de Segurança Nacional e pela edição dos atos institucionais e demais medidas de exceção, que tinham como finalidade a constituição de uma estrutura ideológica, política e administrativa que fornecia sustentação à prática das graves violações. Nessa mesma categoria, são enquadrados os ministros das Forças Armadas que geriam os centros de informações: Centro de Informações do Exército (CIE), Centro de Informações da Marinha (Cenimar) e Centro de Informações de Segurança da Aeronáutica (CISA). 
Já o plano de responsabilidade pelo controle de estruturas e pela gestão de procedimentos é relacionado àqueles que, mesmo não tendo praticado diretamente as graves violações de direitos humanos, permitiram, através de omissão ou conduta comissiva, que essas violações sucedessem, de forma sistemática ou ocasional, nas unidades estatais que estavam sob sua administração. Por exemplo, os oficiais do Exército que dirigiam unidades do DOI, cuja principal função, conforme o apurado, era a prática sistemática de graves violações dos direitos humanos. Logo, com base em seu poder funcional e hierárquico, tais autores orientavam as atividades empreendidas nestes órgãos.

Finalmente, a responsabilidade pela autoria direta se refere aos agentes que, sob coordenação e subordinação hierárquica, executaram ou deram causa de forma direta e imediata às graves violações de direitos humanos. Nesta categoria são enquadrados aqueles que atuaram pessoalmente na prática de tortura, execução e morte de opositores, desaparecimentos forçados e ocultação de cadáveres.

Considerando-se os supracitados planos de responsabilidade apontados pela CNV seria possível realizar uma analogia às teorias sobre autoria no plano do Direito Penal Internacional, principalmente a Teoria do Domínio por Organização, formulada pelo penalista alemão Claus Roxin, em 1963. O domínio do fato em virtude de "aparatos organizados de poder" apresenta uma forma de autoria mediata dos "homens de trás" (ou "autores de escritório”). Isto porque o aparato de poder é utilizado como o instrumento que assegura o domínio sobre o resultado a ser alcançado. Desse modo, para que se possa atribuir o domínio do fato aos homens de trás, Roxin sugere quatro fatores: o poder de mando, a desvinculação do direito pelo aparato de poder, a fungibilidade do executor direto e a disposição essencialmente elevada dos executores ao fato (ROXIN, 2006).

Primeiramente, o autor mediato será aquele com "poder de mando" dentro de uma organização, que é conduzida rigorosamente, e o exerce para produzir realizações típicas. Essa teoria reconhece que pode haver uma cadeia de autoria mediatos, ou seja, podem estar um atrás do outro, localizados em diferentes níveis de hierarquia de mando. Já a desvinculação do Direito pelo aparato de poder sugere que tal aparato é um pressuposto indispensável do domínio da organização. Isto não quer dizer que o aparato de poder precisa 
ter se desvinculado do Direito em todos os aspectos, mas apenas em relação aos tipos penais realizados por ele. E, ademais, tal desvinculação do Direito não interessa na perspectiva do antigo sistema, mas se trata de uma avaliação jurídica atualizada. Quanto à fungibilidade do executor direto, Roxin defende que o cumprimento das ordens do "homem de trás" é assegurado porque muitos potenciais executores encontram-se à sua disposição, ou seja, tais indivíduos são substituíveis e, deste modo, a produção do resultado é garantida. Por fim, tem- se a disposição essencialmente elevada dos executores ao fato, que nada mais é do que uma disposição incondicional do executor direto em cumprir o tipo penal. Devido a influência do aparato de poder, tais autores podem ser levados a uma adesão irrefletida a condutas ou também podem ser guiados por um "obsequioso zelo excessivo", por motivos tais como ambição na carreira, ostentação, deslumbramento ideológico e mesmo impulsos sádicos ou criminosos. Contudo, deve-se ter em mente que sua responsabilidade não é excluída em razão disso (ROXIN, 2006).

Diante de todo o exposto, a teoria de Roxin oferece abrigo aos níveis de participação em âmbito administrativo indicados no Relatório Final da CNV. A Teoria do Domínio por Organização apresenta a possibilidade de imputação de responsabilidade criminal aos membros da alta cúpula do Regime Civil- Militar, aos dirigentes dos aparelhos repressivos das Forças Armadas e aos perpetradores diretos das graves violações de direitos humanos.

Identifica-se na teoria de Roxin os chamados "autores por condução", agentes que planejariam e organizariam os crimes estando inseridos nos níveis mais elevados da organização. Diante da Teoria do Domínio da Organização, a responsabilidade pelo ato cometido aumentaria de acordo com a maior distância ocupada por uma pessoa no quadro de organização da execução do delito, isto é, cresceria de acordo com o maior nível de comando (AMBOS, 2008).

Um exemplo deste tipo pode ser encontrado na condenação do ex-presidente do Peru, Alberto Fujimori, pela Corte Suprema de Justiça do Peru, em 2009. Fujimori foi condenado por homicídio qualificado e lesões corporais graves nos casos Barrios Altos e La Cantuta, além do crime de sequestro agravado no caso Sótanos. O Tribunal considerou que ao ocupar o cargo mais alto do Estado, ele exerceu seu poder mando na condução de uma política de 
Estado contra os considerados subversivos (DUTRA, 2012).

Por conseguinte, os "autores por organização" seriam aqueles pertencentes ao escalão intermediário da organização e exerceriam, assim, parcela de controle (AMBOS, 2008). Neste plano, encontram-se os chefes militares que, de acordo com o Art. 28 do Estatuto de Roma, são criminalmente responsáveis por crimes que tenham sido cometidos por forças sob seu comando e controle efetivos, ou mesmo que por falta de um controle apropriado sobre suas forças.

Este tipo de responsabilização pode ser verificado na decisão da $5^{\mathrm{a}}$ Turma do $\mathrm{BGH}$ (Tribunal Federal de Justiça da Alemanha), em 1994, no que tange aos homicídios praticados pelos guardas de fronteira contra os fugitivos da antiga República Democrática Alemã. Os acusados, dirigentes da organização hierárquica militar, foram considerados como autores dos homicídios visto que haviam ordenado aos atiradores situados sobre o Muro de Berlim que efetuassem disparos contra os fugitivos da RDA. Assim, foi invocada a Teoria da Autoria Mediata em virtude do Domínio da Organização, resguardada a responsabilidade penal dos guardas da fronteira (DUTRA, 2012).

Por sua vez, a responsabilidade pela autoria direta identifica-se com os autores executivos, isto é, os executores do delito de acordo com a Teoria do Domínio da Organização. Somente neste terceiro plano de responsabilização é possível que se discuta a existência de causas excludentes de responsabilidade, a saber: incapacidade mental e intoxicação (que não podem ser alegadas no caso de crimes contra a humanidade), além de legítima defesa e o estado de necessidade por coação ou ameaça (AMBOS, 2008).

Conforme apontado pela CNV, verifica-se uma cadeia de comando desde a Presidência da República, passando pelos oficiais que dirigiam o DOI, por exemplo. Em uma sucessão de "homens de trás" que se utilizam do aparato de poder do Estado, tem-se ordens emanadas de "cima" (desde as diretrizes políticas desenhadas pela Presidência) para os executores diretos das graves violações de direitos humanos. Devido ao reconhecimento de uma política de Estado repressiva que ensejava tais violações, estes "homens de trás" seriam autores mediatos para Roxin. Em relação à desvinculação do Direito, é notório que as execuções, torturas e 
desaparecimentos forçados não estavam amparados por uma base legal e ocorriam de forma oculta, não tendo sido admitidos oficialmente. No que tange à fungibilidade e à disposição dos executores diretos, nota-se no caso brasileiro uma quantidade expressiva de agentes públicos que, no "cumprimento de seu dever funcional", atuaram diretamente nas mortes e torturas. Muitos destes agentes, inclusive, foram condecorados com a Medalha do Pacificador $^{9}$ e ascenderam na carreira por conta dos serviços prestados durante o período repressivo.

\section{Conclusão}

Com o presente trabalho objetivou-se analisar as implicações da indicação de autoria das graves violações de Direitos Humanos pelo Relatório Final da CNV no atual cenário político-jurídico brasileiro. Diante da interpretação realizada até o momento pelo STF, a Lei de Anistia de 1979 encontra-se vigente, impossibilitando o tratamento jurisdicional das graves violações perpetradas pelos agentes públicos durante a Ditadura Civil-Militar. Nesse contexto, às vítimas encontraram-se abertas as vias extrajudiciais que, em um primeiro momento, primaram essencialmente por uma reparação econômica e moral.

Após a bem-sucedida iniciativa das Caravanas da Anistia, a instituição de uma Comissão Nacional da Verdade abriu um novo e importantíssimo capítulo nos rumos da justiça de transição brasileira. Cumprindo seu papel de comissão da verdade, a CNV efetivou o direito à verdade, em âmbito individual e coletivo, recontando a história do período ao contestar as falácias disseminadas pela narrativa dos "vencedores". Ao mesmo tempo, permitiu que os agentes do Estado viessem à público contar suas versões sobre os fatos, propiciando inclusive a oportunidade aos perpetradores de assunção de culpa e, posteriormente, a concessão de perdão individualizado das vítimas e de seus familiares. Assim, foi-lhes proporcionada a chance de protagonizar o processo de restauração da convivência social no país junto às vítimas do Regime.

Contudo, não se deve associar a concessão de perdão individualizado do vitimado

\footnotetext{
9 "Dos 16 convocados, 11 receberam a Medalha do Pacificador com Palma, uma das principais honrarias do Exército Brasileiro, mas que ficou marcada por ter sido concedida a inúmeros militares sob os quais recaem acusações de graves violações de direitos humanos durante a ditadura". Disponível em: 〈http://www.cnv.gov.br/outros-destaques/502-cnvconvoca-16-agentes-da-repressao-para-depor-em-brasilia.html>. Acesso em: 27 nov. 2015.
} 
(proeminente à "justiça das vítimas") com a impunidade dos agentes diante dos crimes cometidos. Conforme evidenciado, há efeitos sociais que perpassam os danos à vítima direta $\mathrm{e}$ aos seus familiares, atingindo toda a coletividade. A grosso modo, pode-se dizer que estão intrinsicamente relacionados ao interesse coletivo da sociedade no rompimento das tramas sociais do crime em um contexto democrático. Sob esta ótica, a política não pode se construir por cima de cadáveres, devendo-se levar a sério os mortos e as injustiças que se fizeram a eles para que se avance no processo de consolidação da democracia. Há, portanto, a necessidade de assunção da responsabilidade histórica, concebendo-se a responsabilidade dos governos democráticos diante do legado das graves violações de Direitos Humanos que os precede (MATE, 2008b).

A recomendação da CNV quanto à apuração de responsabilidade na esfera judicial coaduna com a ideia de que não é possível esquecer o passado e mirar para frente, para o futuro, como se o mundo começasse a ser construído no momento presente. Os governos democráticos têm a responsabilidade de assegurar o direito das vítimas e de toda a população à verdade dos fatos, sem que se furtem a adotar medidas jurisdicionais apropriadas e eficazes quanto aos perpetradores. Isto porque, conforme consolidado internacionalmente, o direito inalienável à verdade e a luta contra a impunidade encontram-se relacionados, traduzindo-se no binômio "Verdade e Justiça". Tal é evidente na redação do Conjunto atualizado de princípios da ONU, que esclarece que a impunidade ocorre diante da incapacidade dos Estados em observar o direito inalienável à verdade e de adotar medidas apropriadas quanto aos perpetradores.

Nessa dinâmica, o Relatório Final da CNV destaca a participação individual de agentes públicos por atos cometidos de forma sistemática, amparados por uma Política de Estado repressiva, durante a Ditadura Civil-Militar. O nome dos algozes passou a constar em um rol disponível a toda a população brasileira, por meio do sítio institucional da Comissão. Ali, através de uma simples busca, pode-se ter acesso à conduta individualizada de um agente em um caso específico de grave violação. Ao mesmo tempo, tem-se o reconhecimento de que esses atos eram ensejados por uma política estatal desenhada pela Presidência da República, responsável pela edição dos atos institucionais e pela adoção da Doutrina de Segurança Nacional. Portanto, tais violações não se perfaziam por atos isolados de agentes 
insubordinados e diante do desconhecimento da alta cúpula do regime, mas emanavam de uma cadeia de comando na qual cada ator teria sua parcela de responsabilidade diante da grave violação empreendida.

Ao reconhecer o legado das graves violações de Direitos Humanos e recomendar a responsabilização dos perpetradores com base em planos de participação que encontram paralelos no Direito Penal Internacional, a CNV aponta o caminho para a superação de um ciclo de impunidade que dura mais de 30 anos. Em consonância com o Sistema Internacional de Proteção dos Direitos Humanos e os julgados da Corte IDH, o Relatório desconstrói o entendimento majoritário do STF quanto a aplicação da Lei de Anistia às graves violações perpetradas por agentes estatais durante a Ditadura Civil-Militar. Destaque-se que se trata de um Relatório de caráter oficial, resultado de uma Comissão constituída por Lei que supera o entendimento recente da mais alta instância do Poder Judiciário brasileiro, ao passo que também fornece importantes indícios para a imputação de responsabilidade aos autores elencados.

Por fim, a potencialidade do Relatório Final da CNV traduz-se na sua capacidade de transformação legal e institucional do atual cenário brasileiro, em consonância com a normativa internacional dos Direitos Humanos. Não se trata da conclusão do processo de transição, ao contrário, o Relatório oferece fundamentação à luta da sociedade civil contra a impunidade dos perpetradores, sem olvidar que a consolidação democrática passa por políticas voltadas à reinserção social das vítimas, à reconstrução da memória e verdade dos fatos.

\section{REFERÊNCIAS BIBLIOGRÁFICAS:}

AMBOS, Kai. A parte geral do Direito Penal internacional: bases para uma elaboração dogmática. São Paulo: RT, 2008.

BRASIL. Lei 6.683, de 28 de agosto de 1979.

BRASIL. Lei 12.528, de 18 de novembro de 2011.

CARLET, Flávia; FERREIRA, Kelen M.M.; FRANTZ, Daniela; JUNIOR, Paulo A.P.; OLIVEIRA, Vanda D.F. de. As Caravanas de Anistia: Um mecanismo privilegiado da justiça de transição brasileira. Disponível em:

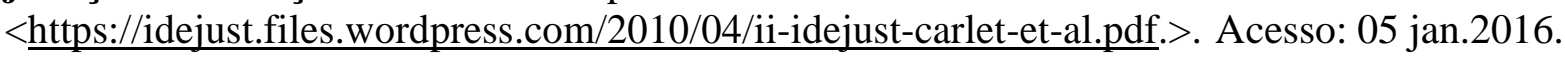

DUTRA, Bruna Martins Amorim. Criminal responsability in the crimes committed by organized structures of power: jurisprudence analysis in the light of International Criminal Law. In: Revista da Faculdade de Direito da UERJ, V.2, n.22, jul./dez.2012. 
GÓMEZ, José María. A justiça transicional e o imprevisível jogo entre a política, a memória e a justiça. In: Re-vista: Verdade Justiça Memória. Rio de Janeiro, abr. 2014. Disponível em: $<$ http://www.revistavjm.com.br/artigos/a-justica-transicional-e-o imprevisivel-jogo-entre-apolitica-a-memoria-e-a-justica/>. Acesso em: 27 nov. 2015.

HAYNER, Priscilla B. Unspeakable Truths: Transitional Justice and the Challenge of Truth Commissions. New York, N.Y: Routledge, 2011.

KIM, H. and SIKKINK, K. Explaining the Deterrence Effect of Human Rights Prosecutions for Transitional Countries. In: International Studies Quarterly, 54: 939-963, 2010.

MATE, Reyes. Justicia de las víctimas: Terrorismo, memoria, reconciliación. Barcelona: Anthoropos Editorial, 2008a.

.Fundamentos de una filosofia de la memória.In: RUIZ,Castor Bartolomé. Justiça e Memória:Para uma crítica ética da violência.São Leopoldo:Editora Unisinos, 2008b.

Paz o reconciliacón. El País: Archivo, 17 set. 1999. Disponível em: <http://elpais.com/diario/1999/09/17/opinion/937519206_850215.htl. Acesso :27 nov. 2015.

MÉNDEZ, Juan E. Accountability for past abuses. Human Rights Quarterly. v.19,1997.p. 255-282.

ORGANIZAÇÃO DAS NAÇÕES UNIDAS. La cuestión de la impunidad de los autores de violaciones de los derechos humanos (civiles y políticos). Informe final elaborado e revisado por M. Louis Joinet. E/CN. 4/Sub. 2/1997/20/Rev. 12 de outubro de 1997. Disponível em: <http://www.derechos.org/nizkor/doc/joinete.html〉. Acesso em: 27 nov. 2015.

ORGANIZAÇÃO DAS NAÇÕES UNIDAS. Conjunto de princípios atualizado para a proteção e a promoção dos direitos humanos mediante a luta contra a impunidade. Informe de Diane Orentlicher, especialista independente. E/CN.4/2005/102/Add.1, 8 de fev. 2005. Disponível: < http://ap.ohchr.org/documents/dpage_s.aspx?si=E/cn.4/2005/102/Add.1 Acesso em: 27 nov. 2015.

RELATÓRIO DA COMISSÃO NACIONAL DA VERDADE. Volume I, Cap. 1, 7, 16, 18; Volume II, Cap. 1. Disponível em: < http://www.cnv.gov.br/>. Acesso em: 27 nov. 2015.

RONIGER, Luis; SZNAJDER, Mario. Ao leitor Brasileiro. In: O legado das graves violações dos direitos humanos no cone sul. São Paulo: Perspectiva, 2004.

ROXIN, Claus. O domínio por organização como forma independente de autoria mediata. In: Revista Eletrônica Acadêmica de Direito Law E-journal PANÓPTICA. Disponível em: < http://www.panoptica.org/seer/index.php/op/article/view/86>. Acesso em: 27 nov. 2015.

RUIZ, C.M.M.B. Debates. In: MATE, Reyes. Justicia de las víctimas: Terrorismo, memoria, reconciliación. Barcelona: Anthoropos Editorial, 2008. 
Justiça anamnética e alteridade ferida, por uma justiça das vítimas.In: ASSY, Bethania et al (Org.). Direitos Humanos: justiça, verdade e memória. Rio de Janeiro: Editora Lumen Juris, 2012. p. 49-78.

TORELLY, Marcelo D. Justiça de Transição e Estado Constitucional de Direito. Belo Horizonte: Fórum, 2012.

ZAMORA, José A. História, Memória e Justiça: Da justiça transicional à justiça anamnética. In: SILVA FILHO, José Carlos Moreira da et al (Org.). Justiça de Transição nas Américas: olhares interdisciplinares, fundamentos e padrões de efetivação. Belo Horizonte: Fórum, 2013. p. 21-46. 